\title{
EN ROUTE TO A PhD: MAPPING THE JOURNEY THROUGH A SENSEMAKING LENS
}

\author{
M. Coetzee \\ Department of Communication \\ Central University of Technology, Free State \\ Bloemfontein, South Africa \\ e-mail: ecoetzee@cut.ac.za / https://orcid.org/0000-0001-5422-1747
}

\section{A. Wilkinson}

Research and supervision mentor

University of the Free State

Bloemfontein, South Africa

e-mail: wilkac3@gmail.com / https://orcid.org/0000-0002-6031-3768

\section{ABSTRACT}

Doing a PhD is for most scholars a demanding and emotionally strenuous experience, frequently resulting in potentially promising researchers succumbing to despair soon after embarking on the journey. However, those who complete their doctoral studies recollect subsequently both the frustrations and exciting experiences encountered. This article describes one researcher's ruminations to make sense of the extensive systematic analysis utilised in a quest to obtain a PhD and to understand the academic essence of the scholarly contribution of her $\mathrm{PhD}$. Using the seven fundamental properties of Weick's (1995) sensemaking theory as the theoretical lens, the researcher reflects on the experiences and observations faced en route to completing her $\mathrm{PhD}$. The seven properties form the backdrop of the researcher's qualitative sensemaking methodology in which she formulated three key phases to illustrate her sensemaking road, namely Mapping the Journey, Travelling the Road, and Reaching the Destination. This article reinforces the extent of the challenges a PhD study holds and provides detail of and insight into the application of the sensemaking theory that may be useful to postgraduate researchers and supervisors involved in qualitative inquiry.

Keywords: sensemaking, sensemaking theory, Weick, systematic analysis, systematic review, doctoral studies, PhD journey, qualitative inquiry, case study, reflection

\section{INTRODUCTION}

$\mathrm{A} \mathrm{PhD} \mathrm{is} \mathrm{often} \mathrm{envisioned} \mathrm{as} \mathrm{a} \mathrm{journey,} \mathrm{although} \mathrm{not} \mathrm{always} \mathrm{an} \mathrm{easy} \mathrm{or} \mathrm{gratifying} \mathrm{one.} \mathrm{Many}$ scholars, upon completion of a $\mathrm{PhD}$, feel compelled to describe what they went through during the years of their study, as I (the first author) do. Reflecting on my $\mathrm{PhD}$ journey, recalling the excitements and disappointments I experienced, I considered various approaches to convey my 
story in such a way that it will benefit other researchers. It was during these deliberations that I called to mind the sensemaking theory as articulated by Karl Weick. Weick's (1995) sensemaking theory with its seven properties (identity, social activities, enactment, cues, plausibility, retrospection, and ongoing processes) formed the ideal theoretical lens (Berberich $2016,325)$ to illuminate my memories and communicate how I made sense of my research journey - from the first to the last step.

This article commences with an overview of the concept of sensemaking as both theory and methodology, with an explanation of the seven properties of sensemaking to expand insight into these properties and to illustrate how they contribute to understanding a variety of phenomena. This is followed by the three-phase sensemaking methodology I developed as a conceptual map of the way I made sense of my PhD journey. During the first phase, Mapping the Journey, I used the sensemaking properties identity and social context as the basis for the features character, community, and context of my map to illustrate how my character, community, and social environment influenced my decision to do a $\mathrm{PhD}$ and the topic I chose. The second phase, Travelling the Road, builds on the sensemaking properties enacting, extracting cues, and reflecting in my map in order to shed light on the research processes I followed, how I found sources, and the way data from these sources were extracted, analysed, and explained. The last phase, Reaching the Destination - with the features accept, adapt, and attain - uses the sensemaking properties plausibility, retrospection, and the ongoing nature of sensemaking to tell the story of the difficult final stages of completing the $\mathrm{PhD}$, as well as the joys of finally obtaining the degree certificate. This is followed by a reflection on the academic essence of the $\mathrm{PhD}$ through a systematic analysis in which the emphasis falls on my own learning and possible scholarly contributions. In the conclusion, I point out the value of a sensemaking lens in qualitative inquiry, which may be useful to other $\mathrm{PhD}$ candidates and their supervisors.

\section{THE SENSEMAKING “LENS"}

Weick $(1995,4)$ defines sensemaking as "the making of sense"; an action people take to understand the situations in which they find themselves. Weick (1995) advises the reader to think of sensemaking as "a frame of mind about frames of mind": to think how we can apprehend and integrate the information or ideas we have into something that we know, and then to articulate that what we think we know into that something we need to know (McNamara 2015, 2; Tsvetkov 2017, 1). In other words, sensemaking enables us to articulate the unknown; to make sense of "streams of input by putting labels on what we experience" (Ancona 2011, 4) in order to reduce confusion (Lyhne 2010, 2). 
Sensemaking is considered an interpretative, explanatory process (Weick cited in Berberich 2016, 94). Via interpretation and analysis, on a conscious and sub-conscious level, ambiguities and uncertainties are eradicated while the individual searches for similarities and differences in data in order to establish meaning (Paull, Boudville and Sitlington 2013, 3; Namvar et al. 2018, 2). Weick $(1995,8,61)$ observes that sensemaking and interpretation, although closely related, are two quite different processes. Interpretation, as an important component of sensemaking, assumes that there is already "something there which needs to be discovered" (Namvar et al. 2018, 2); that a "frame of meaning" (Weick 1995, 8) exists to which new cues can be added in order to consciously create a new meaning. If there is no frame and one must be created or discovered, we rely on sensemaking (Weick cited in Maitlis and Christianson 2014, 109). Sensemaking is therefore described as a knowledge-creating process based on interpretations, decisions, and individual perceptions, or, as Sutcliffe (cited in Maitlis and Christianson 2014, 109) notes, "sensemaking is about the ways people construct what they interpret".

Major contributors to sensemaking theory interpret sensemaking in various ways. Whereas Weick (1995) understood sensemaking to be a process in which people (intentionally or unintentionally) take steps to understand situations, Dervin (cited in Littlejohn and Foss 2009,879 ) views sensemaking as a methodology to investigate human assumptions about the nature of information and communication. Klein (cited in Jones 2015, 2), on the other hand, focuses on the individual's mental model or frame, or on "what goes on inside people's heads" (Littlejohn and Foss 2009, 879) when they structure information when they make sense of external data. Russell, Pirolli and Card (cited in Jones 2015, 2) also focus on the interpretation of external data, but from an informational, theoretical view of making sense of the data. Although most sensemaking theories also focus on the ability of humans to deliberately try to make sense, Weick's (1995) theory, and the various aspects he divided sensemaking into, allows for personal interpretation of a situation and enable the development of a personal philosophy (Littlejohn and Foss 2009, 879), which allows me to make sense of my journey based on my individual experiences.

\section{THE SEVEN ASPECTS OF SENSEMAKING}

Weick (1995) divided sensemaking into seven properties or aspects: the construction of identity, social activities and roles, enactment, the extraction and identifying of cues, plausibility, retrospective sensemaking, and the ongoing aspects of sensemaking (Weick 1993, 636; Weick 1995, 17; McNamara 2015, 2; Tsvetkov 2017, 1). These seven aspects become entwined as individuals construct new realities from the things they want to make sense of 
(Currie and Brown 2003, 571; Maitlis 2005, 21).

\section{Construction of identity}

Identity and identity construction are central to sensemaking. Weick (1995) explains that identity is who we understand ourselves to be in relation to the world, who we want to be, and who we become while trying to make sense (Josefsson 2015, 70; Weick 1995, 18-20; Cherneski 2018, 60; Perryman 2011, 47). Sensemaking therefore influences who we see as our real self when we look through the lens of "the constructed self" (O'Connor 2015, 102). The self we see, however, is our ideal self, seen in a self-made world according to our custom-made identity (Perryman 2011, 47). This identity, this "sense of who one is", influences how we select, interpret, and retain information from "what is out there" (Weick 2001, 461).

\section{Social activities and roles}

Weick $(1995,39)$ claims that sensemaking is a social activity, dependent on our culture and current social interaction (Weick 2001, 340, 461). Social interaction is, however, influenced by our social norms, upbringing, and education (Fellows and Liu 2016, 248; Tsvetkov 2017, 2; Namvar et al. 2018, 2). Although Maitlis and Christianson (2014, 64) consider whether sensemaking takes place within a person or between people, they regard sensemaking as "a fundamentally social process" (Maitlis 2005, 21), because even if individuals make sense on their own, their thoughts, feelings, and behaviours are influenced by the "actual, imagined, or implied presence of others" (Allport cited in Maitlis and Christianson 2014, 66). To infer and give meaning to experiences, people communicate with others via verbal and non-verbal means to seek information, or to exchange stories, rumours, and ideas (Maitlis and Christianson 2014, 64). During this social process, sensemaking is "negotiated, contested and mutually coconstructed" (Maitlis and Christianson 2014, 66).

\section{Enactment of reality and the environment}

Enactment relates to the social construction of meaning (Berberich 2016, 96). In this regard, Weick $(1995,90)$ explains that enactment takes place through cognitive processes and preconceptions about the environment or situation we are in. According to Andrews $(1995,1)$, we change and shape the nature of this enacted environment (or context) because we are constantly taking deliberate action to make sense of what we encounter. This process of enactment never ends; the environment and the aspects we are making sense of perpetually influence each other (Muhren, Van den Eede and Van de Walle 2008, 317; Currie and Brown $2003,570)$. Weick $(1995,30)$ remarks that our first reaction when attempting to create meaning 
is by talking about the problem or event in an effort to interpret what we experience, think, or feel. Various authors (Cherneski 2018, 62; Perryman 2011, 49; Namvar et al. 2018, 2; Andrews 1995, 1; Josefsson 2015, 73) list other actions people undertake to enact with the environment; for example, to inspect, interpret, interact, talk, ask questions, discuss options, contemplate, comprehend, look for data, explain, predict, structure new processes, etc. An enactment environment is, in other words, "a map of if-then assertions" of perceived or purposefully extracted cues created via one or more of these actions (Weick 1995, 49, 54; Andrews 1995, 1), which can either make sense of what already happened or of what will or may happen (Maitlis and Christianson 2014, 94).

\section{Identifying and extracting cues}

Observing or extracting cues may be triggered by a need for knowledge, by incomprehensible events or occurrences, by violated expectations, by actions that are surprising or confusing, or by uncertainty (Maitlis 2005, 21). People's perceptions of such experiences depend on the impact of the occurrence, or on each person's objectivity about the experience (Maitlis and Christianson 2014, 70). Sensemaking involves putting cues into frameworks, mental maps, or representations of one kind or another when interpreting the signals (cues) they perceive (Maitlis and Christianson 2014, 63, 96; Fellows and Liu 2016, 246). These interpretations depend on the situation (context) and the personality of the individual (Maitlis 2005, 21), influenced by filters such as own interests, personal dispositions, and a person's unconsciousness (University of Twente 2017, 2). These filters may restrain a person from noticing all the applicable cues or may even influence the decision about which cues to pay attention to and which not (Muhren et al. 2008, 315).

\section{Accepting plausibility rather than accuracy}

Based on the credibility of cues, sensemaking involves developing - and being content with plausible understandings and meanings of an ever-changing world (Ancona 2011, 5; Weick $2001,462)$; or as Weick $(1995,62)$ phrases it: "I need to know enough about what I think to get on with my projects, but no more, which means sufficiency and plausibility take precedence over accuracy". Weick $(1995,55-58)$ declares that accuracy is not a necessity; accuracy takes time and cannot always be achieved, while, if we accept plausibility, we can make sense of events, situations, or experiences and move on (O’Connor 2015, 44; Tsvetkov 2017, 2). Ancona $(2011,7)$ states in this regard that to act may be more important than to search for the right answer, which we "maybe will never find anyway". Furthermore, sensemaking means that we develop plausible images (frames) retrospectively and not necessarily correct, to rationalise 
what we are doing or experiencing (Weick, Sutcliffe and Obstfeld 2005, 409; Paull et al. 2013, 3 ), connecting cues and frames to create a map of what is going on (Maitlis and Sonenshein $2010,551)$.

\section{Retrospective sensemaking}

Retrospection as an aspect of sensemaking refers to the scrutiny of earlier decisions, experiences, and events in order to make meaning (Muhren et al. 2008, 317; Perryman 2011, 61; Berberich 2016, 102). Weick $(1995,24)$ explains that we can only understand what we experienced after something occurred and we reflect on it to make plausible sense retrospectively. Weick uses the expression "How can I know what I think until I see what I say?" to explain that only through reflection can we understand previous experiences and will be able to take applicable action (Weick 1995, 29; Tsvetkov 2017, 2; Cherneski 2018, 74). Understanding is an ongoing process in sensemaking, which is influenced by social interactions and perceived or extracted cues (Cherneski 2018, 59). Maitlis and Christianson (2014, 94) explain that the other side of retrospective sensemaking is "prospective" sensemaking, referring to the intentional consideration of probable future impacts of actions and non-actions (Maitlis and Christianson 2014, 96), using an "if-then" argument about perceived or purposefully extracted cues (Weick 1995, 49, 54; Andrews 1995, 1).

\section{Ongoing aspects of sensemaking}

Sensemaking is a dynamic, ongoing process of repetitive meaning construction without a beginning or formal end in which "past experience is projected upon possible futures" (Weick 1995, 43). Numerous authors (Weick 1993, 635; Muhren et al. 2008, 317; Weick 1995, 49; University of Twente 2017, 2; Cherneski 2018, 59) explain how sensemaking takes place in a continuing stream of change because the world, our interactions with the world, and our understanding of the world are constantly changing while we continually seek to make retrospective sense of what occurs.

Although each of the aspects of Weick's sensemaking theory can be used and applied in various disciplines, situations, and circumstances, for the purpose of this article the aspects will form the backbone of my methodological approach to illustrate and make sense of my $\mathrm{PhD}$ journey.

\section{MY THREE-PHASE SENSEMAKING METHODOLOGY}

Dervin $(1992,63,84)$ states that sensemaking is a method; a qualitative methodological approach to study a person's construction of ideas to make sense of past experiences. According 
to McMillan and Schumacher $(2001,378)$, a descriptive, explanatory qualitative research approach is concerned with the relationships between events and meanings from an individual's perspective. A case study research design is both descriptive and qualitative, focuses on a specific case or entity (my story), set within a real-world context (my study), with a view to understand the issue from the perspective of the individual (me) (Denzin and Lincoln 2011, 9; Harrison et al. 2017, 5). Flyvbjerg $(2011,313)$ states that good (case) studies should be read as narratives in their entirety; my narrative is a "truthful description" of my experiences, with "plausible explanations" that may benefit other researchers and academics (Mouton 1996, 102).

In investigating my “case”, I based my methodology on Weick's (1995) sensemaking theory by dividing the seven properties into the three main phases of the journey; each with three core features to illustrate my personal interpretation of the journey:

1. Mapping the journey: The first two aspects of Weick's (1995) sensemaking theory, identity and social context, form the roots of the features, character, community, and context. These aspects influenced my choice of $\mathrm{PhD}$ research topic and research design, and had an influence on the way I started and planned the research; in other words, the way I mapped my journey (Weick 2001, 9);

2. Travelling the road: The three sensemaking aspects - enacting (the academic environment of this research), extracting cues (from the research environment and the research population), and reflecting (on the findings of the coding process and the experience of doing a $\mathrm{PhD}$ ) - are the foundations of the features of the second phase. These features illustrate the research road I travelled with all the ups and downs I encountered.

3. Reaching the destination: The last three sensemaking aspects - plausibility, retrospection, and the ongoing nature of sensemaking - are depicted in the third phase as the end of the journey with the features accept, adapt, and attain. Every researcher must at one point or another accept plausibility, reflect on the situation, adapt where needed, and write up the final version of the dissertation in order to attain a $\mathrm{PhD}$ and go on with life.

Weick $(2001,9)$ uses the term "cartography" to explain how we can map our reality in such a way that we, and other people, can continually make sense of our current reality (Wilkins and Thompson 1991, 20). Fellows and Liu $(2016,249)$, on the other hand, describe the map as a cognitive structure used to interpret a situation. The content of this structure includes the things a person knows, assumes, or believes, while the structure shows how the content is "arranged, connected or studied" (Finkelstein and Hambrick cited in Fellows and Liu 2016, 246). The cognitive structure I used as my method to map the sensemaking process for this $\mathrm{PhD}$ journey 
can be illustrated in three consecutive phases (illustrated in Figure 1), each with three sensemaking features.

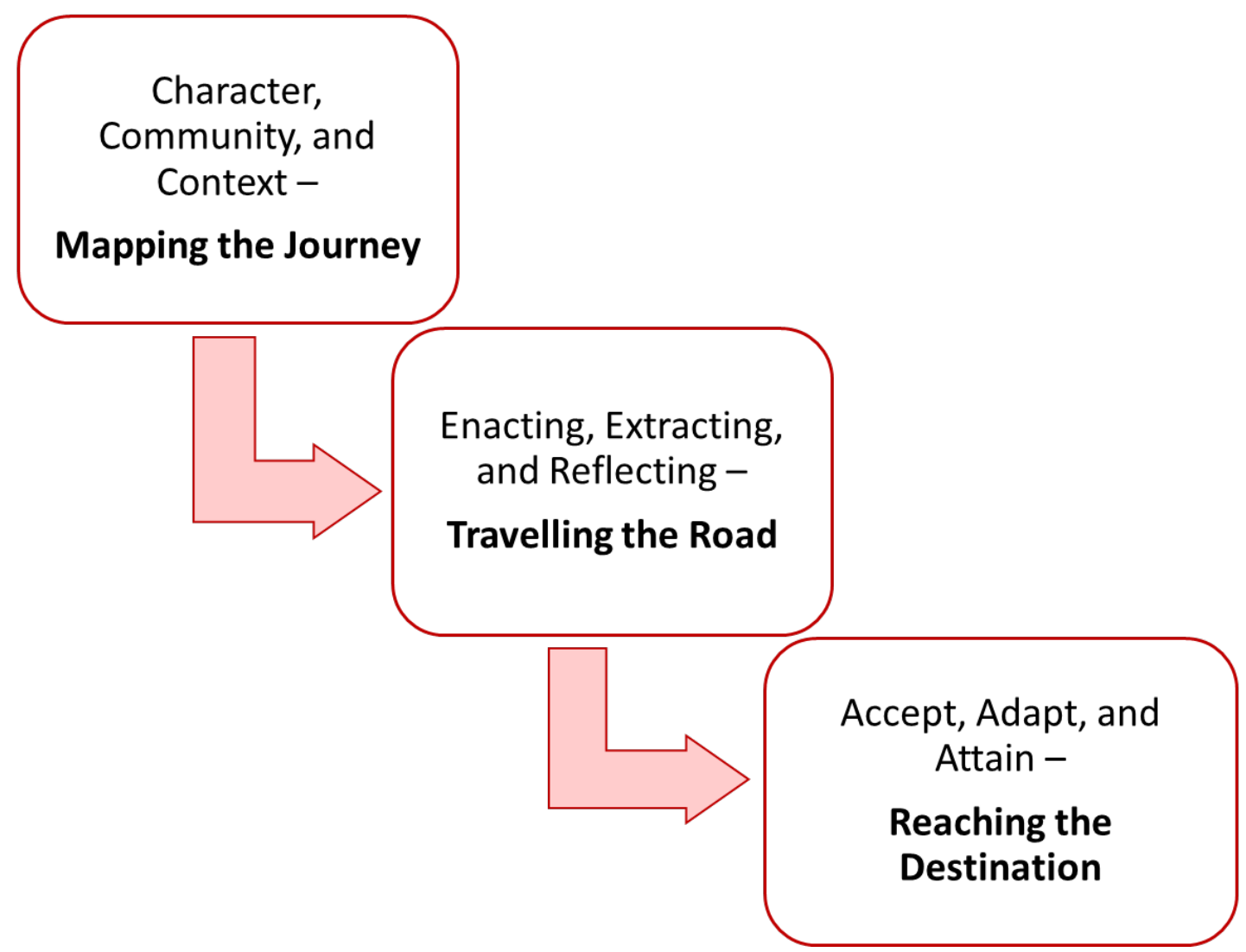

Figure 1: Cognitive structure to make sense of my PhD journey

By following the road, broken into the three phases depicted in Figure 1, I was able to make sense of my journey, and in doing so, attempted to explain my experiences in such a way that it might be of value to other researchers.

\section{Mapping the journey: Character, community, and context}

When I first thought about doing a PhD, I had no idea what I was getting myself into. As a lecturer in Communication Science, teaching a module about social media to a class of 300 second-year students from diverse backgrounds, I had a vague inkling that maybe I should investigate the use of social media (which was my speciality field) to support my teaching efforts. In the end I registered for a $\mathrm{PhD}$ in Communication Science with the focus on the use of social media as computer-mediated communication in South African higher education, as an interdisciplinary study.

When I look back at my doctoral beginnings, I know I was influenced by who I was at that time: a lecturer with a unique set of life and teaching experiences. My identity (Weick 
2001, 461) was based on the beliefs and values of my culture, my social environment, and on my perception of my "real self" (O’Connor 2015, 20; Perryman 2011, 47). Overwhelmed by my work as a lecturer and struggling to relate to the students due to the influence of social media, I found myself desperately searching for solutions to ease the troubles of teaching. According to Wenger $(1998,149)$, "we define who we are by the familiar and unfamiliar and by where we have been and where we are going" - who and where I was inevitably influenced my choice of research topic, although at the time it was more a cry for help than a research problem. The search for a solution for my problem became my $\mathrm{PhD}$ topic and was the starting point of a seemingly unending journey of four years.

But the departure was not easy. Finding information to base an initial literature study on was easy and in a sense exhilarating; via the university library, online databases, and the Internet, I had access to an abundance of articles, books, and e-journals. It soon became clear that, as a result of the continuous developments in technology, research about the possible use of social media in higher education has exploded and a myriad of seemingly applicable documents were available. Within a couple of weeks, I had accumulated hundreds of documents, some only loosely related to the topic, without me having an idea of where I was heading. It was at this point that I realised that without clear direction of the road I was to follow, the $\mathrm{PhD}$ would forever only be a dream covered by layers of documents.

My next step was to seek guidance from my supervisor, colleagues, and the information specialists at the university library. Social interaction with professional people whom I could relate to (Berberich 2016, 109; University of Twente 2017, 2), as well as discussions with my family and friends, helped me to focus and find direction. During the first months after my decision to embark on this journey, I experienced a great deal of anxiety - what if I cannot do this? What if my research idea is ridiculous or my work is not good enough? What if I cannot juggle my work and my research at the same time and fail in one or the other? It was in regard to these fears that my social support system was indispensable. These social interactions helped me to make sense (Weick 1995, 39) of where my study was heading.

Finding an appropriate methodology was one of the most difficult aspects I experienced when beginning with my $\mathrm{PhD}$. The problem started with the realisation that my search for a way to teach using social media was inundated by an overwhelming amount of information and a mass of published and grey literature on the use of social media in higher education, which made it difficult to find primary research evidence about how social media could be utilised for teaching and learning (Tharyan 1998, 135).

Guided by my supervisor and supported by the information officer at the library, I developed systems to sensibly narrow down the number of retrieved documents, to focus my 
search according to specific criteria in order to find only relevant research reports published within a specific timeframe, to sort through the material to investigate applicable methodologies and procedures and, in doing so, finding the direction I was searching for. After much consideration, based on an interpretive constructivist philosophy, I chose systematic review as methodology because it seemed to be the best research method to interpret the large volumes of research information (Petticrew and Roberts 2006, 266; Yuan and Hunt 2009, 1086). I came to the conclusion that although a systematic analysis is a very challenging methodology, the accumulation of global knowledge (with application to a local context) would make a far more significant contribution to an already extensively researched area than through (yet another) educational intervention. This step, to decide on a research method, was the actual beginning of my journey, but, as McGinnis $(2010,3514)$ opined about the road to a $\mathrm{PhD}$ : "The truth is that while life may get better, it doesn't necessarily get easier'.

\section{Traveling the road: Enacting, extracting, and reflecting}

Yuan and Hunt $(2009,1086)$ assert that meticulous research methods should be used when conducting a systematic review, planned according to a detailed protocol, with accurately listed keywords and search terms, and a specified timeframe in order to retrieve everything of relevance (Petticrew and Roberts 2006, 44). For me, that meant long, lonely hours in the library or behind the computer, not talking to anyone, with a growing feeling of desperate confusion over the unbelievable mass of literature available from which I was attempting to find meaning (Berberich 2016,96). It was during this time that I most often lost motivation; for days on end I would procrastinate, deliberately not make time for the search, or just ignoring my inner voice that told me to work (Weick 1995, 40). But eventually there was progress, as well as a certain amount of satisfaction in finding numerous documents relating to the topic of my study. There must, however, be a cut-off point for every search, otherwise the search would never end and the study will never commence. Even in searching for applicable documents one must accept plausibility (Weick 1995, 62).

Although it is difficult to indicate the precise number of possible relevant documents I retrieved, an estimated 2400 documents were screened for potential inclusion in the study, of which 1398 were eventually selected to form the population of the study (Coetzee 2015, 156). DeCoster $(2004,7)$ states that it is possible to discard over 90 per cent of the source documents originally found, but because missing relevant studies can negatively influence the review, and all measures should be taken to find as many applicable sources as possible. After an exasperating elimination process based on predefined criteria, a final list of 220 selected documents was recorded - an estimated 9 per cent of all the documents originally retrieved. 
The pleasure of compiling this final list was short-lived, as I was not prepared for the magnitude of the task ahead: the tedious job of analysing the contents of these documents - to enact the "environment" generated by my research (Weick 1995, 90) - was overwhelming. The logical next step in sensemaking was to select applicable data from the material that could provide plausible answers to my research problem (Lyhne 2010, 3). I decided to use an explorative qualitative research design to identify and extract relevant data from the selected documents. Data extraction refers to the process of locating and recording relevant data (cues) from selected studies through inductive category coding (Maykut and Morehouse 1994, 127; Hewitt-Taylor 2001, 39). Thomas $(2006,238)$ explains that the primary purpose of the inductive approach is to "allow research findings to emerge from the frequent, dominant, or significant themes inherent in raw data". These themes were the cues I was probing for - the "directional signals for sensemaking" as Perryman $(2011,51)$ calls them. Weick $(1995,50)$ refers to these extracted cues as "simple, familiar structures that are seeds from which people develop a larger sense of what may be occurring". Coding and the relating of concepts are imperative to the discovery of patterns among data because it reduces information by clustering data into categories from which conclusions may be drawn. I read each of the documents, made notes, and looked for patterns and commonalities that reflected categories or themes (Johnson and Christensen 2007, 19/4).

During this process, which took me almost a year, I experienced many days when I felt that I could not make sense of anything; there was just too much data, too many documents, and too many aspects to think of. There was also the persistent feeling that my research was inherently flawed, that it was not going anywhere. During this year I also had to learn how to juggle work, family life, and research, and stay motivated at the same time.

According to Ancona $(2011,6)$, sensemaking often involves moving from the simple (collecting and processing information) to the complex and back again. The move to the complex occurs as patterns are identified and new information is labelled and categorised. The complex then becomes simple again, although with a higher level of understanding (Ancon $2011,6)$. I realised that this phase of my research was the "moving to the complex" - taking the research others had done, tearing it apart, mixing it like the ingredients of a recipe, listing commonalities and similarities, and attempting to find applicable data in each document from which I could create a simple, understandable framework to answer my research problem.

At the end of that year I had 52 sets of data containing an unbelievably vast amount of information, and it felt as if there were still a lot more to retrieve. But, as McNamara $(2015,2)$ observes, we have neither the perceptual nor the cognitive resources to know everything exhaustively, therefore at one time or another we must move on. At this stage, after the 
information from the 220 documents were extracted and labelled as best as I could, I was ready to take on the analysis of the extracted data (Lyhne 2010, 3).

Analysis was just as time-consuming and tiresome as coding, and in the end the amount of data compelled me to make use of two electronic data-analysing systems: NVivo Qualitative Data Analysing Software and Dedoose Web Application Software. These helped me to identify aspects from the data that otherwise would not have been discovered (Berberich 2016, 15), and various interesting and important aspects emerged from the analysed data. After all the sleepless nights and days filled with irritations and frustrations, the excitement of these results motivated me to work with new enthusiasm towards finalising the dissertation.

\section{Reaching the destination: Accept, adapt, and attain}

Even if the coding process is done exactly according to the predefined protocol, one of the setbacks of a systematic analysis is the wide array of data results one can get. The electronic analysis provided me with many interesting, but also varying, sets of results and the challenge was to compile one final set of directives from these to address the research problem. I found that many days I lost focus of exactly what I was looking for in the data, and I played around with the statistics, graphs, and tables that emerged from the data that were unrelated to the research focus. Even in looking for patterns and answers, at some point one must stop probing and accept the results.

Ancona $(2011,10)$ asserts that it is often necessary to "move outside a system in order to see the patters within". Through further reflection and interpretation, I was able to create "new knowledge" (Maitlis and Sonenshein 2010, 551) from the retrieved data and design a framework to provide directives towards effective teaching and learning using social media in higher education. Designing a theoretical framework after years of hard work and listing the directives to accompany the framework were the most exciting experience of my journey I can recall. My joy, however, was again short-lived.

The last stretch of the road consisted of endless corrections and changes to the text. During the last few months, I learned to accept criticism, to hold my tongue, and to rewrite my dissertation a hundred times over. The best thing about this is that I now know exactly how my students feel, and I can treat them with the same patience and sympathy my supervisor showed me. The stress sometimes left my physically depleted, but you are too far in the race to quit, and too desperate to finish to care. As much as I enjoyed finding results from the data analysis, so much more I disliked this phase of the journey.

But it was not the end. After submitting the final copies for examination, the seemingly unending period of waiting began, with ceaseless thoughts of failure, nerve-wracking thoughts 
of "what if?". And, when the results came in, I again had to accept, adapt, and hold my tongue. Recommended changes and corrections felt like unclimbable mountains. At this stage all I cared about was to submit the final version of my $\mathrm{PhD}$ - not to get recognition, not to have my name in capital letters somewhere, not even to walk the stage. At the end of the journey - like the end of an Iron Man Competition - you just want the misery to end. To attain the degree and go on with a normal life like other people. But in the end one attains the $\mathrm{PhD}$, walks the stage, prints the copies, and publishes the results.

The day I received the news that the final version of my dissertation was at last accepted, I was not even happy; just relieved, and thankful. The joy, however, resurfaced the day of my graduation when I saw my proud family and friends in the crowd, when I walked next to my supervisor in my red cape, standing on the stage while the dean read my name, and afterwards when I received compliments from colleagues and members of the university's academic assembly while my family took hundreds of pictures.

A colleague once told me that having the title of doctor is like passing Grade 12; suddenly you are no longer a child, you are somehow different from the person you used to be the day before. I experienced that within days after graduation. Suddenly I (imagined I) was being treated with more respect than before by colleagues and students. I looked with new eyes at the future of my career, and I was motivated like never before to face the unavoidable ups and downs of the academic environment. I was proud to show off my new status, able to have my voice heard in academic meetings, and I knew that I could talk with authority on my topic. Even now, a few years after attaining the $\mathrm{PhD}$, I realise how much I benefitted from the difficult road I walked. Based on the magnitude of information delivered via the systematic analysis, my dissertation delivered many publication opportunities, although some of the information must be updated due to the dynamic character of social media. With every year passing by, with every dissertation I supervise, and with every article I write, I realise how much I learned en route to my $\mathrm{PhD}$. I know now that my life changed somewhere during and right after graduation day; that not only did I fulfil a life-long dream, but that I reached new heights from where I was able to build a new academic career.

\section{THE ACADEMIC ESSENCE OF MY PHD JOURNEY}

With Weick's (1995) notion of ongoing sensemaking in mind - described as a dynamic process with past experiences projected onto achievable futures - I conclude my sensemaking effort by reflecting on the academic essence of my PhD journey. I was led by two questions: what have I learned from my PhD in an academic sense, and what might others gain from my scholarly contribution? 
From a sensemaking (and realistic) perspective, I realise I cannot regard the set of directives I have formulated for the application of social media as computer-mediated communication in South African higher education as my major scholarly contribution that will make ongoing sense in a dynamic field and ever-changing digital world. I realised, however, that my $\mathrm{PhD}$ experience as a whole rather illustrated and exemplified my personal learning process. I learned through a series of processes, and through these processes I attained my goals. In a dynamic, interconnected way, each process also became a product, a contribution; something concrete others can also learn from and apply in their studies.

A systematic analysis contains many processes. It begins with the very important formulation of a goal and research questions. These should be very clear and focused in order to serve as the compass that guides the whole journey, including theory and methodology.

Theoretically, my $\mathrm{PhD}$ integrated theory from three different fields or disciplines. I therefore regard the conceptual framework designed for the study as a contribution to the research fields of Communication Science, Computer-Mediated Communication (CMC) and of Higher Education Studies. The conceptual framework of my study comprised perspectives gained by means of theoretical "lenses": the "communication-centred lens", the "social mediacentred lens" and the "education-centred lens". The framework, although specifically designed for my study, can be adapted and refined by other researchers to be used in related research and related fields.

In accordance with the conceptual framework, my $\mathrm{PhD}$ included three extensive literature review chapters: one related to social media, one to communication theories, and one to applicable teaching and learning theories. In these chapters, relevant models and principles were described and gradually integrated into the building of a model that theoretically represents key principles for the use of social media in higher education classrooms. A range of similarities between communication theory and learning theory was identified, with communication at the very core of effective social media use in an educational context. This applies to all attributes of effective teaching and learning with technology; whether active learning, participation, engagement, feedback, or any other attribute. The study therefore highlighted the important link between Communication Science and Education as disciplines.

Earlier in the article I covered the painstaking but vital process of searching and selecting the sample of documents to be included in a systematic analysis. I grew immensely through this process that took me almost a year. I believe that my description of the research strategy followed can serve as an important guide for new researchers who want to follow this route in their studies. The same applies to the enormous process of analysing an overwhelming amount of data (also described earlier in this article). Without the use of qualitative software, a thorough 
analysis would not have been possible. I gained much by attending courses on the use of such software and by teaching myself the more advanced attributes of the programs. I can testify that successful analysis can become a life-changing learning process for any scholar and the fruits will be of an ongoing nature - whether in own research or in postgraduate supervision.

Another example of the learning process I underwent while doing my $\mathrm{PhD}$ - and a possible exemplary process - is the multitude of figures and tables I have used in my thesis. I regard such representations as characteristic of a systematic analysis - a quick and effective way of introducing the reader to a large amount of data. Included are, inter alia, various tables, many types of graphs, a GIS (Geographical Information System) map of the distribution of the institutions represented in the sample of documents, and more than 40 figures illustrating a wide variety of facts and findings of the study.

Ultimately, I want to see the academic essence of my contribution in its totality of integrated processed and products - a practical illustration to others of what a systematic analysis on $\mathrm{PhD}$ level entails.

\section{CONCLUSION}

This article provided a short, focused overview of Weick's (1995) sensemaking theory to pave the way towards creating a cognitive structure or "map" of the sensemaking process to portray my reflections of my $\mathrm{PhD}$ journey. By writing this article, I was able to make sense of my studies by grouping my experiences into three phases, each with three features. From the first of the three phases, I learned that my background, history, and personality had a definite influence on the choice of my topic and on the first steps I took of undertaking a $\mathrm{PhD}$. Coming from an informational background made it easy for me to find information, which set the stage to make use of a systematic analysis as the only methodology to analyse all the information. Secondly, at this stage of this journey, there is no turning back. Just reaching the second phase took a great deal of time, and I had to put in a lot of work and effort and had to struggle through all the protocols of the systematic analysis to find the answers I was looking for. I realised that using a systematic analysis as a research method was not the easy way, but in the end, it was rewarding - especially because of all the information ascertained. Lastly, while contemplating the last phase, I came to the realisation that this was actually the most difficult part of the road. Most of the work is done, and you think you see the light at the end of the tunnel. But to get there you must cross many bridges, step over many obstacles, and learn to wait at many stop signs. But the last phase also brings you to the gratifying end of the road: when you attain your $\mathrm{PhD}$ and are equipped to continue building your career. The end then becomes a new beginning in a dynamic, ever-changing world. In a reflection on the academic essence of my scholarly 
contribution, I have pointed out the interconnectedness between processes and products, which all form part of personal learning and what others might learn from the study.

To conclude, the reflective value of the sensemaking theory for qualitative inquiry is unquestionable. I experienced the theory and its various dimensions as highly adaptable to a specific cause and mode of inquiry, giving rise to the development of an appropriate methodological approach that fits any researcher's personal philosophy. The three-part cognitive structure (see Figure 1) that guided the thinking in my reflective endeavour is certainly only one of many constructive ways in which researchers can make use of a sensemaking lens in their attempts to map - and make sense of - personal experiences.

\section{REFERENCES}

Ancona, D. 2011. Sensemaking: Framing and acting in the unknown. In The handbook for teaching leadership, ed. S. A. Snook, N. N. Nohria and R. Khurana, 3-20. Thousand Oaks, USA: Sage Publications.

Andrews, J. 1995. The University of Alberta's cognitive science dictionary. http://penta.ufrgs.br/ edu/telelab/3/enactmen.htm

Berberich, J. 2016. An exploration of survivors' experience of organizational downsizing: A sensemaking perspective. Unpublished doctoral dissertation, University of Gloucestershire, United Kingdom. http://eprints.glos.ac.uk/4132/1/PhD\%20thesis\%20Joerg\%20Berberich_Final \%20submission_Redacted\%20for\%20signature\%20only.pdf

Cherneski, J. 2018. Zebras showing their stripes: A critical sensemaking study of the discursive construction and gendering of women CSR leaders. Unpublished doctoral dissertation, University of Athabasca, Canada. https://dt.athabascau.ca/jspui/ bitstream/10791/258/11/Zebras\%20 Showing\%20their\%20Stripes\%20-\%20Dissertation \%20-\%20JCherneski\%20-\%20FINAL.pdf

Coetzee, E. J. S. 2015. Directives for the application of social media as computer-mediated communication in South African higher education. Unpublished doctoral dissertation, University of the Free State, South Africa.

Currie, G. and A. Brown. 2003. A narratological approach to understanding processes of organizing in a UK hospital. Human Relations 56: 563-586.

DeCoster, J. 2004. Meta-analysis notes. http://www.stat_help.com/notes.html

Denzin, N. K. and Y. S. Lincoln. 2011. Introduction: The discipline and practice of qualitative research. In The Sage handbook of qualitative research, ed. N. K. Denzin and Y. S. Lincoln, 1-20. $4^{\text {th }}$ Edition. Thousand Oaks, USA: Sage Publications.

Dervin, B. 1992. From the mind's eye of the user: The sense-making qualitative-quantitative methodology. In Qualitative Research in Information Management 9, ed. J.D. Glazier and R.R. Powell, 61-84. England and Wales: Libraries Unlimited

Fellows, R. and A. Liu. 2016. Sensemaking in the cross-cultural contexts of projects. International Journal of Project Management 34: 246-257.

Flyvbjerg, B. 2011. Case study. In The Sage handbook of qualitative research, ed. N. K. Denzin and Y. S. Lincoln, 301-316. $4^{\text {th }}$ Edition. Thousand Oaks, USA: Sage Publications.

Harrison, H., M. Birks, R. Franklin and J. Mills. 2017. Case study research: Foundations and methodological orientations. Forum: Qualitative Social Research 18(1): 1-17.

Hewitt-Taylor, J. 2001. Use of constant comparative analysis in qualitative research. Nursing Standard 15(42): 39-42. 
Johnson, B. and L. Christensen. 2007. Educational research: Quantitative, qualitative, and mixed approaches. Thousand Oaks, USA: Sage Publications.

Jones, P. H. 2015. Sensemaking methodology: A liberation theory of communicative agency. https://www.epicpeople.org/sensemaking-methodology/

Josefsson, M. Y. 2015. Social foundation of sense making: Four case studies. Unpublished doctoral dissertation, Manchester Metropolitan University, United Kingdom. https://e-space.mmu.ac.uk/ 593692/1/Thesis\%20Final\%20-\%20Corrections-MagnusThinkPad.pdf

Littlejohn, S. W. and K. A. Foss. (Ed.). 2009. Encyclopedia of Communication Theory. Los Angeles, USA: Sage Publications.

Lyhne, I. 2010. Making sense of impact assessments: Impact assessments as sense-making. Paper for poster presentation at the International Association for Impact Assessment AIAI10 Conference, Geneva.

Maitlis, S. 2005. The social process of organizational sensemaking. Academic Management Journal 48(1): 21-49.

Maitlis, S. and M. Christianson. 2014. Sensemaking in organisations: Taking stock and moving forward. The Academy of Management Annals 8(1): 57-125.

Maitlis, S. and S. Sonenshein. 2010. Sensemaking in crisis and change: Inspiration and insights from Weick (1988). Journal of Management Studies 47(3): 551-580.

Maykut, P. and R. Morehouse. 1994. Beginning qualitative research: A philosophic and practical guide. Great Britain: The Falmer Press.

McGinnis, L. F. 2010. Life after the PhD: What I wish I had known sooner. In Proceedings of the 2010 Winter Simulation Conference, ed. B. Johansson, S. Jain, J. Montoya-Torres, J. Hugan and E. Yücesan, 3514-3519. Baltimore, USA: IEEE.

McMillan, J. H. and S. Schumacher. 2001. Research in education: A conceptual introduction. New York, USA: Longman.

McNamara, L. A. 2015. Sensemaking in organizations: Reflections on Karl Weick and social theory. https://www.epicpeople.org/sensemaking-in-organizations/

Mouton, J. 1996. Understanding social research. Pretoria, South Africa: Van Schaik Publishers.

Muhren, W. J., G. G. P. Van den Eede and B. A. Van de Walle. 2008. Sensemaking as a methodology for ISCRAM research: Information processing in an ongoing crisis. In Proceedings of the $5^{\text {th }}$ International Conference on Information Systems for Crisis Response and Management (ISCRAM 2008), ed. F. Fiedrich and B. A. Van de Walle, 315-323. Washington, D.C., USA: ISCRAM.

Namvar, M., J. L. Cybulski, C. S. C. Phang, Y. S. Ee and K. T. L. Tan. 2018. Simplifying sensemaking: Concept, process, strengths, shortcomings, and ways forward for information systems in contemporary business environments. Australasian Journal of Information Systems 22: 1-10.

O'Connor, M. 2015. Understanding sensemaking in organisational change: A cognitive mapping approach. Unpublished doctoral dissertation, University of Birmingham, United Kingdom. http://etheses.bham.ac.uk/7164/9/O'Connor17PhD.pdf

Paull, M., I. Boudville and H. Sitlington. 2013. Using sensemaking as a diagnostic tool in the analysis of qualitative data. The Qualitative Report 18(27): 1-12.

Perryman, C. L. 2011. The sense-making practices of hospital librarians. Unpublished doctoral dissertation, University of North Carolina, United States of America. https://www.researchgate. net/publication/280043263_The_sensemaking_practices_of_hospital_librarians_doctoral_dissert ation

Petticrew, M. and H. Roberts. 2006. Systematic reviews in social sciences: A practical handbook. Abington, UK: Blackwell Publishing.

Tharyan, P. 1998. The relevance of meta-analysis, systematic reviews and the Cochrane collaboration to clinical psychiatry. Indian Journal of Psychiatry 40(2): 135-148. 
Thomas, D. R. 2006. A general inductive approach for analyzing qualitative evaluation data. American Journal of Evaluation 27(2): 237-246.

Tsvetkov, Z. 2017. Summary of sensemaking in organisations: Reflections on Karl Weick and social theory. http://www.enliveningedge.org/reviews/summary-sensemaking-organisations-reflections -karl-weick-social-theory/

University of Twente. 2017. Managing (life) is about making sense. https://www.utwente.nl/ $\mathrm{en} / \mathrm{bms} /$ communication-theories/sorted-by-cluster/Interpersonal $\% 20$ Communication $\% 20 \mathrm{and} \% 20$ Relations/Sensemaking-1/

Weick, K. E. 1993. Collapse of sensemaking in organizations: The Mann Gulch disaster. Administrative Science Quarterly 38: 628-652.

Weick, K. E. 1995. Sensemaking in organizations. Thousand Oaks, USA: Sage Publications.

Weick, K. E. 2001. Making sense of the organization. Oxford, UK: Blackwell.

Weick, K. E., K. M. Sutcliffe and D. Obstfeld. 2005. Organizing and the process of sensemaking. Organization Science 16(4): 409-421.

Wenger, R. 1998. Communities of practice: Learning, meaning and identity. Cambridge, UK: Cambridge University Press.

Wilkins, A. and M. P. Thompson. 1991. On getting the story crooked (and straight). Journal of Organisational Change Management 4(3): 18-26.

Yuan, Y. and R. H. Hunt. 2009. Systematic reviews: The good, the bad, and the ugly. American Journal of Gastroenterology 104: 1086-1092. 